\title{
Dietary supplementation with arachidonic acid but not eicosapentaenoic or docosahexaenoic acids alter lipids metabolism in C57BL/6J mice
}

\author{
Sameh Magdeldin ${ }^{1,3}$, Yaser Elewa ${ }^{2,3}$, Takako Ikeda ${ }^{3}$, Junko Ikei ${ }^{3}$, Ying Zhang ${ }^{3}$, Bo Xu $\mathrm{Xu}^{3}$, Masaaki \\ Nameta ${ }^{3}$, Hidehiko Fujinaka ${ }^{3}$, Yutaka Yoshida ${ }^{3}$, Eishin Yaoita ${ }^{3}$ and Tadashi Yamamoto ${ }^{3}$ \\ ${ }^{1}$ Department of Physiology, Faculty of Veterinary Medicine, Suez Canal University, Egypt \\ 2 Department of Histology, Faculty of Veterinary Medicine, Zagazig University, Egypt \\ ${ }^{3}$ Department of Structural Pathology, Institute of Nephrology, Graduate School of Medical and Dental Sciences, Niigata \\ University, Japan
}

\begin{abstract}
In order to investigate the effects of dietary supplementation rich in omega 3 and omega 6 fatty acids, we set up an experiment of twenty four C57BL/6J male mice segregated into 3 groups: normal diet (ND), omega 3 polyunsaturated fatty acid (n-3 PUFA,) and omega 6 (n-6 PUFA). At the end of the experiment that lasted for 1 month, food consumption of ND and n-3 PUFA were similar while it decreased in n-6 PUFA group. Total cholesterol, triglycerides, free fatty acids, and phospholipids profiles were increased in n-6 PUFA. LDL decreased in n-3 PUFA while increased in n-6 PUFA fed mice comparing to control group. On the other hand, there was no difference between treatments in HDL and glucose levels. Expression of leptin $(o b)$ gene transcripts in epididymal fat were significantly elevated in n-6 PUFA mice compared to ND and n-3 PUFA groups while hypothalamic ob receptor A (obRa) mRNA did not changed in response to diet regimes. Transmission and scanning electron microscopy showed different degrees in fatty changes in the liver of both PUFA groups including lipid droplet infiltration and Ito cells with over accumulated lipids. In conclusion, under PUFA dietary supplementation, the hyperlipidemic status and elevated $o b$ expression of n-6 PUFA but not n-3 PUFA fed mice suggests altered lipid metabolism between PUFA groups and/or different endocrine involvement. Moreover, the coincidently structural changes observed in liver of this group direct us to call for further studies to investigate the anti-obesity effect and safety of these PUFA under high supplementation condition.
\end{abstract}

Key words: Arachidonic acid — Eicosapentaenoic acid — Docosahexaenoic acid - Leptin — Leptin receptor

\begin{abstract}
Abbreviations: AA, arachidonic acid; DHA, docosahexaenoic acid; EPA, eicosapentaenoic acid; FA, fatty acid; FFA, free fatty acid; HDL, high density lipoprotein; LA, linoleic acid; LDL, low density lipoprotein; ND, normal diet; $o b$, leptin; $o b R$, leptin receptor; PL, phospholipid; PUFA, polyunsaturated fatty acid; TC, total cholesterol; TG, triglyceride.
\end{abstract}

\section{Introduction}

Polyunsaturated fatty acid (PUFA), are long-chain fatty acids (FA) containing two or more double bonds (Rese-

Correspondence to: Sameh Magdeldin, Department of Structural Pathology Institute of Nephrology, Graduate School of Medical and Dental Sciences, Niigata University, 1-757 Asahimachi-dori, Japan E-mail: samehmagd@med.niigata-u.ac.jp samehmagd@yahoo.com land et al. 2001; Schmitz and Ecker 2008). Among them, omega 3 and omega 6 are considered to be essential FA (Li et al. 2008). Eicosapentaenoic acid (EPA, $20: 5$ n-3) and docosahexaenoic acid (DHA, $22: 6 \mathrm{n}-3$ ) are two important long-chain unsaturated FA in essential omega 3 family while arachidonic acid (22:4 n-6) is a member of omega 6 family (Tsuzuki et al. 2005). Under normal PUFA supplementation, it has been reported that n-3 and n-6 PUFA may improve lipid metabolism (Tsuzuki et al. 2005; Li et al. 2008). However, there were no previous data 
examined the physiological effects of these FA under high fat diet regimen.

Leptin $(o b)$, an adipocyte-specific hormone, plays a key role in regulating energy intake and energy expenditure including the regulation (decrease) of appetite and (increase) of metabolism (Geerts and Hautekeete 1997; Trayhurn et al. 1999). This action is mediated through a membrane protein $o b$ receptors $(o b R)$ located mainly in choroid plexus and hypothalamus (Geerts and Hautekeete 1997). However, there is lacking information regarding the physiological response of prolonged usage of high fat diet on these receptors.

The initial impetus for the present study is to examine the impacts of n-3 PUFA and n-6 PUFA (under high supplementation) on plasma lipogram (total blood cholesterol, triglyceride, phospholipid, free FA, and low and high density lipoproteins) together with the response pattern of $o b$ and $o b R a$ genes against different PUFAs. Moreover, we also speculated the ultrastructural changes of liver as an important site for fat storage.

\section{Materials and Methods}

\section{Animals}

Twenty four C57BL/6J male mice (8 weeks old, $23.4 \pm$ $0.2 \mathrm{~g}$ ) bred at the Animal Care Research Center (Niigata University, Japan) were used in the current study. All animals were treated following the statement of animal use according to the Animal Care Research Center (Niigata University, Japan). They were individually housed in a temperature and humidity controlled room $\left(22 \pm 2^{\circ} \mathrm{C}\right.$ and
$45 \%$, respectively) with 12 -h light/12-h dark cycle and were given $12.5 \mathrm{~g} / \mathrm{animal} /$ week ( $100 \mathrm{~g} / \mathrm{group} /$ week) to prescribed freshly prepared diets (see Table 1) and filtered tap water throughout the study. Care was taken to minimize feed spillage for accurate calculations.

\section{Diets and experimental design}

After habituation to commercial mice chow for 1 week, mice were then randomly segregated according to the administered diet into 3 groups ( $n=8$ /group): group assigned to normal diet (ND), omega 3 polyunsaturated fatty acid (n-3 PUFA), and omega 6 (n-6 PUFA) for 1 month (Wang et al. 2002). All diet ingredients were purchased from Oriental Yeast Industry (Chiba, Japan) except EPA and DHA which were from Natural Factors (Everett, Canada). Freshly prepared diet was considered in order to protect and preserve FA component from oxidation process.

\section{Sampling}

At the end of experiment, mice were stunted and decapitated without being fasted prior to sampling. Blood samples were collected before decapitation either by heparinized microhematocrit (Thermo Scientific, Japan) from the orbital medial canthus or in some cases by heart puncture using heparinzed syringe. Blood samples were centrifuged at $12,000 \mathrm{rpm}(9000 \times \mathrm{g})$ at $4^{\circ} \mathrm{C}$ for $10 \mathrm{~min}$ and kept in $-20^{\circ} \mathrm{C}$ until analysis. Epididymal fat (white adipose tissue), hypothalamus (area underneath hypophysis) and liver samples were dissected and snap frozen in $-80^{\circ} \mathrm{C}$ by

Table 1. Composition of ND, n-3 PUFA n-6 PUFA diet

\begin{tabular}{|c|c|c|c|}
\hline Ingredient & ND & n-3 PUFA & n-6 PUFA \\
\hline Casein purified high nitrogen & \multicolumn{3}{|c|}{$295 \mathrm{~g}(29.5 \%)$} \\
\hline Sucrose & \multicolumn{3}{|c|}{$348 \mathrm{~g}(34.5 \%)$} \\
\hline Corn starch & $250 \mathrm{~g}(28 \%)$ & \multicolumn{2}{|c|}{$125 \mathrm{~g}(12.5 \%)$} \\
\hline AA (n-6) (92\% purity) & $10 \mathrm{ml}(1 \%)$ & - & $155 \mathrm{ml}(15.5 \%)$ \\
\hline $\begin{array}{l}\text { EPA and DHA } \\
(n-3)(89 \% \text { purity })\end{array}$ & $10 \mathrm{ml}(1 \%)$ & $\begin{array}{c}155 \mathrm{ml}(15.5 \%) \\
(46.5 \mathrm{~g} \mathrm{EPA} \text { and } 23.25 \mathrm{~g} \text { DHA }) \\
\end{array}$ & - \\
\hline Soybean oil ${ }^{\star}$ & $10 \mathrm{ml}(1 \%)$ & - & - \\
\hline $\begin{array}{l}\text { Mixed vitamins } \\
\text { (B, E, A, D-3, K-1, folic acid, biotin, nicotinic acid) }\end{array}$ & \multicolumn{3}{|c|}{$22 \mathrm{~g}(2.2 \%)$} \\
\hline $\begin{array}{l}\text { Mixed minerals } \\
(\mathrm{Ca}, \mathrm{K}, \mathrm{Fe}, \mathrm{Zn}, \mathrm{Mn}, \mathrm{Na}, \mathrm{Cl}, \mathrm{S})\end{array}$ & \multicolumn{3}{|c|}{$51 \mathrm{~g}(5.1 \%)$} \\
\hline $\begin{array}{l}\text { DL-methionin } \\
\text { Total energy }(\mathrm{kcal} / \mathrm{g})\end{array}$ & $\begin{array}{l}4 \mathrm{~g}(0.4 \%) \\
2.6\end{array}$ & $\begin{array}{l}4 \mathrm{~g}(0.4 \%) \\
3.8\end{array}$ & $\begin{array}{l}4 \mathrm{~g}(0.4 \%) \\
3.8\end{array}$ \\
\hline
\end{tabular}

All ingredients expressed in weight and percentage of total volume. ND, normal diet; n-3 and n- 6 PUFA, omega 3 and omega 6 polyunsaturated fatty acid; AA, arachidonic acid; EPA, eicosapentaenoic acid; DHA, docosahexaenoic acid; ${ }^{*}$ soybean oil was added to supply the minimum requirement of essential FAs to control group according to AIN-93 diet formula. 
submerging in liquid nitrogen for gene quantification. Other hepatic specimens were also sampled and fixed in glutaraldehyde for transmission and scanning electron microscopy (EM). Body weights and food decrement were measured daily.

\section{Plasma measurements}

For lipogram measurements, total cholesterol (TC) was determined using cholesterol oxidase method (SRL, Japan). For accurate triglyceride (TG) and phospholipid (PL) measurements, and to avoid affect by free glycerol, both were measured using glycerol-3-phosphate oxidase method (SRL, Japan). Free FA (FFA), low density lipoprotein (LDL), and high density lipoprotein (HDL) were determined using enzymatic colorimetric kits (SRL, Japan). Glucose was quantified using glucose oxidase method (Wako, Japan). Pre-experimental lipid profile was checked prior to study.

\section{RNA isolation}

Total RNA was isolated using the TRIzol method (Invitrogen, Carlsbad, CA, USA) according to manufacturer's protocol. Briefly, $100 \mathrm{mg}$ of the tissue were homogenized with $1 \mathrm{ml}$ of Trizol reagent using Polytron Heidolph Diax 900 (Sigma-Aldrich, Japan) followed by addition of $200 \mu \mathrm{l}$ of chloroform. Samples were agitated vigorously for $15 \mathrm{~s}$ and centrifuged at $14,500 \mathrm{rpm}(12,000 \times \mathrm{g})$ at $4^{\circ} \mathrm{C}$ for $15 \mathrm{~min}$. The colorless aqueous phase was transferred to new tubes. For RNA precipitation, $500 \mu \mathrm{l}$ of isopropyl alcohol was added to the aqueous phase and incubated for $30 \mathrm{~min}$. Samples were then centrifuged at 14,500 rpm $(12,000 \times g)$ at $4^{\circ} \mathrm{C}$ for $10 \mathrm{~min}$.

After removing the supernatant, RNA wash was performed using $1 \mathrm{ml}$ of $80 \%$ cold ethanol. Samples were vortexed and centrifuged at $9000 \mathrm{rpm}(7500 \times \mathrm{g})$ at $4^{\circ} \mathrm{C}$ for $10 \mathrm{~min}$. Finally, ethanol was decantated, and samples were allowed for air drying before dissolving in diethyl pyrocarbonate water. Assessment of RNA quality and quantity was done using Nanodrop ND-1000 (Thermo Fisher Science, Japan). In all samples, $\mathrm{A}_{260} / \mathrm{A}_{280}$ absorbance ratio were above 1.85 .

\section{Reverse transcription}

First strand cDNA was synthesized using random hexamer primer method. Each reverse transcription (RT) reaction contained $3 \mu \mathrm{g}$ of RNA template, $50 \mathrm{U} / \mu \mathrm{l}$ Superscript II reverse transcriptase, $50 \mathrm{ng} / \mu \mathrm{l}$ random hexamer primers, $10 \mathrm{mmol} / \mathrm{l} \mathrm{dNTPs}$ mix, $40 \mathrm{U} / \mu \mathrm{l}$ RaseOUT, $0.1 \mathrm{~mol} / \mathrm{l} \mathrm{DDT}$ and $10 \times \mathrm{RT}$ buffer $(200 \mathrm{mmol} / \mathrm{l}$ Tris- $\mathrm{HCl}, \mathrm{pH} 8.4 ; 500$ $\mathrm{mmol} / \mathrm{l} \mathrm{KCl}$ ). RT reaction was performed using Takara PCR Thermal Cycler Dice 650 (Otsu, Japan) with cycling conditions of $25^{\circ} \mathrm{C}$ for $10 \mathrm{~min}, 42^{\circ} \mathrm{C}$ for $50 \mathrm{~min}$, and $95^{\circ} \mathrm{C}$ for $3 \mathrm{~min}$.

\section{Polymerase chain reaction}

Gene expressions of $o b, o b R a$ and glyceraldehyde-3-phosphate dehydrogenase (GAPDH), as stable internal control, were measured using thermal cycler (Otsu, Japan). A specific primer pairs were designed using the Primer3 engine (Rozen and Skaletsky, 2000) and shown in Table 2. For polymerase chain reaction (PCR), 0.5 or $1 \mu \mathrm{l} \mathrm{cDNA}$ of RT-template were used for GAPDH or other genes, respectively. The reaction contained a master mix of $10 \times$ PCR buffer $(200 \mathrm{mmol} / \mathrm{l} \mathrm{Tris-HCl} \mathrm{(8.4),} 500 \mathrm{mmol} / \mathrm{l}$ $\mathrm{KCl}), 50 \mathrm{mmol} / \mathrm{l} \mathrm{MgCl}_{2}, 2.5 \mathrm{mmol} / \mathrm{l} \mathrm{dNTP} \mathrm{mix,} 10 \mu \mathrm{mol} / \mathrm{l}$ sense and anti sense primers, $5 \mathrm{U} / \mu \mathrm{l} \mathrm{Taq}$ DNA polymerase, and autoclaved deionized water up to $10 \mu \mathrm{l}$. Bands intensity were quantified using freeware image analysis software NIH image (National Institute of Health, Bethesda, USA).

\section{Transmission EM}

For transmission EM, liver fragments were fixed in 2.5\% glutaraldehyde in $0.1 \mathrm{~mol} / \mathrm{l}$ phosphate buffer $(\mathrm{pH}$ 7.2) for $3 \mathrm{~h}$, postfixed in $1 \%$ osmium tetroxide in $0.1 \mathrm{~mol} / \mathrm{l}$ phosphate buffer, washed twice in the same buffer. Samples were then dehydrated in ascending grades of ethyl alcohol and embedded in Oken EPOK812 resin (Oken Shoi Co., Ltd., Tokyo, Japan). Resin polymerization was accomplished in by incubation of the samples in oven at $60^{\circ} \mathrm{C}$, for $48 \mathrm{~h}$. Ultrathin sections ( 60 and $80 \mathrm{~nm}$ ) were cut and transported to copper grids, stained with uranyl acetate and lead citrate. All samples were analyzed and photographically captured

Table 2. Oligonucleotide sequences and conditions of sense and anti sense primers for $o b, o b R a$ and GAPDH

\begin{tabular}{|l|l|l|c|c|c|c|c|}
\hline & Sense & Anti- sense & $\begin{array}{c}\text { Primer } \\
\text { length } \\
(\mathrm{mer})\end{array}$ & $\begin{array}{c}\text { Annealing } \\
\text { temperature } \\
\left({ }^{\circ} \mathrm{C}\right)\end{array}$ & $\begin{array}{c}\text { GC } \% \\
\text { Product } \\
\text { size } \\
(\mathrm{bp})\end{array}$ & $\begin{array}{c}\text { Accession } \\
\text { number }\end{array}$ \\
\hline$o b$ & TGTTAGAGGGAGGGTGAAGG & ACAGAATGGGTGGGAGACAG & 20 & 59.5 & $55 \%$ & 404 & NM008493 \\
\hline$o b R a$ & CCAGGTGAGGAGCAAGAGAC & CGGAGTCAGGAAGGACACAC & 20 & 60 & $60 \%$ & 683 & NM146146 \\
\hline GAPDH & TAAAGGGCATCCTGGGCTACACT & TTACTCCTTGGAGGCCATGTAGG & 23 & 62 & $52 \%$ & 200 & NM021751 \\
\hline
\end{tabular}

$o b$, leptin; $o b R a$, leptin receptor A; GAPDH; glyceraldehyde-3-phosphate dehydrogenase; GC\%, the ratio between guanine and cytosine. 
using Hitachi H-600A transmission electron microscope (Hitachi Co., Ltd., Tokyo, Japan) according to (Williams and Carter 2006).

\section{Scanning EM}

Specimens were processed following Gabriel (1982). Briefly, samples were fixed in $2.5 \%$ glutaraldehyde in 0.1 mol/l phosphate buffer for 1 day. After initial fixation, the specimens were rinsed several times with phosphate buffered saline (PBS) for $15 \mathrm{~min}$, followed by post fixation with $1 \%$ osmium tetroxide in $0.1 \mathrm{~mol} / 1$ phosphate buffer for $1 \mathrm{~h}$. After rinsing with PBS for a minimum of $15 \mathrm{~min}$, the specimens were dehydrated using a series of graded ethyl alcohols (70\% for $15 \mathrm{~min}, 95 \%$ for $15 \mathrm{~min}$ and 3 changes of $100 \%$ for $10 \mathrm{~min} / \mathrm{each}$ ). From this point on, specimens were subjected to critical point drying using Hitachi HCP-2 (Hitachi Co., Ltd., Tokyo, Japan). After drying, the specimens were mounted on aluminum stubs with adhesive tabs and sputter coated for 3 min using Hitachi E-1030 (Hitachi Co.). Specimens were then ready to be examined on the Hitachi S-550 scanning electron microscope (Hitachi Co.).

\section{Statistical analysis}

Statistical analysis was performed using one way ANOVA followed by Fisher's least significant difference test. $\Delta \Delta \mathrm{C}_{\mathrm{T}}$ for relative gene expression was calculated where $\Delta \Delta \mathrm{C}_{\mathrm{T}}=$ $\Delta \mathrm{C}_{\mathrm{T}}$ test sample $-\Delta \mathrm{C}_{\mathrm{T}}$ calibrator sample. Calculations were carried out using Prism 4 software (Graphpad, USA). A difference was considered to be significant at $p<0.05$.

\section{Results}

\section{Food intake}

At the end of experiment, the average food consumption of ND and n-3 PUFA were 84.6 and $72 \%$, respectively. On the other hand, it decreased to $49 \%$ in $n-6$ PUFA group (Fig. 1).

\section{Body weight}

As shown in Fig. 2, during the first week of our experiment there was no significant difference between experimental groups. At day 7, n-6 PUFA group showed a significant increase $(p<0.05)$ compared to ND and n-3 PUFA groups $(25.7 \pm 0.4 \mathrm{~g}, 23.4 \pm 0.6 \mathrm{~g}$, and $24.4 \pm 0.6 \mathrm{~g})$, respectively. The difference between n-6 PUFA mice versus other groups became highly significant $(p<0.01)$ after 3 weeks where average body weight was $24.5 \pm 0.6 \mathrm{~g}$ for $\mathrm{ND}, 24.8 \pm 0.4 \mathrm{~g}$ for $\mathrm{n}-3$ PUFA and $26.7 \pm 0.4 \mathrm{~g}$ for $\mathrm{n}-6$ PUFA. At the end of the experiment, the average body weight was $24.9 \pm 0.6 \mathrm{~g}, 25.5$ $\pm 0.6 \mathrm{~g}$ and $26.8 \pm 0.3 \mathrm{~g}$ for ND, n-3 PUFA and n- 6 PUFA groups, respectively.

\section{Plasma measurements}

Plasma lipids showed different patterns within each experimental group (Figs. 3 and 4). As shown in Fig. 3, TC, TG and FFA significantly increased $(p<0.01)$ in n-6 PUFA fed group over ND and n-3 PUFA groups.

LDL showed significant drop in n-3 PUFA group compared to control $(p<0.01)$ and n-6 PUFA group $(p<0.001)$.

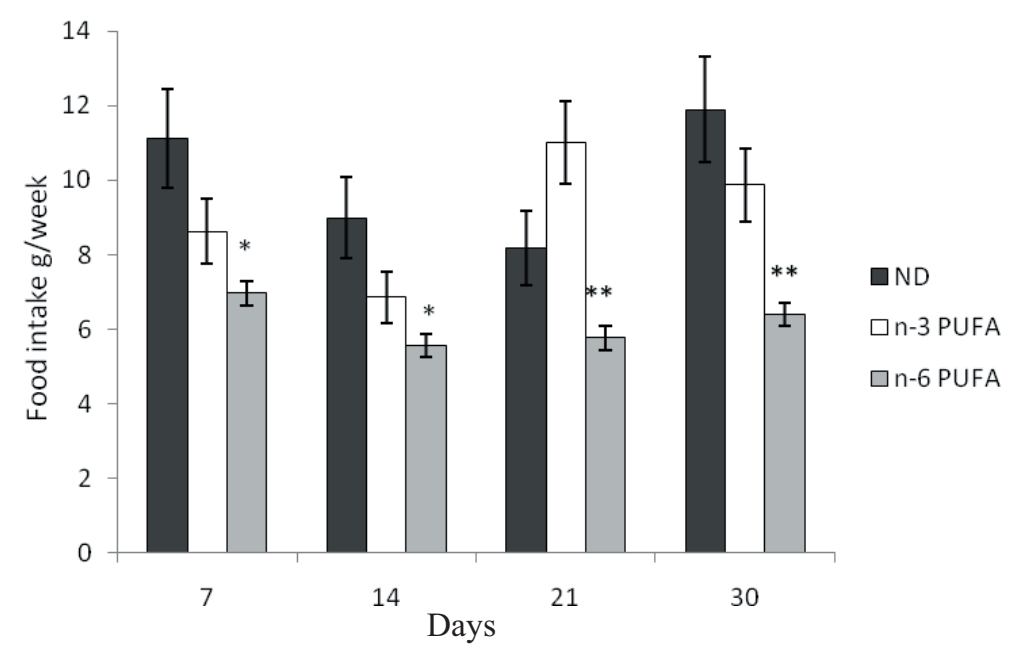

Figure 1. Food intake of ND, n-3 PUFA and n-6 PUFA groups expressed by gram/week. ND, normal group; n-3 PUFA, EPA and DHA diet; n-6 PUFA, AA diet. Values represent mean \pm S.E.M $(n=8) ;{ }^{*} p<0.05,{ }^{* *} p<0.01$ significantly different from other groups at the same point. 


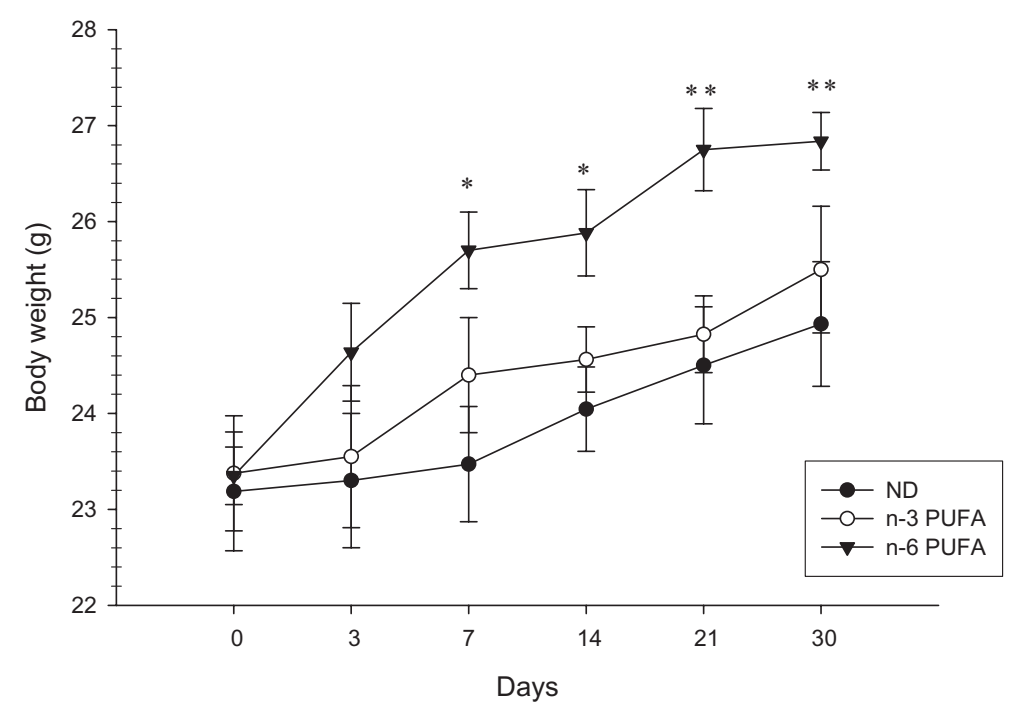

Figure 2. Effects of ND, n-3 PUFA and n-6 PUFA on the average body weights. ND, normal diet; $n-3$ PUFA, EPA and DHA diet; $n-6$ PUFA, AA diet. Values represent mean \pm S.E.M $(n=8) ;{ }^{*} p<0.05,{ }^{* *} p<0.01$ significantly different from other groups at the same point.
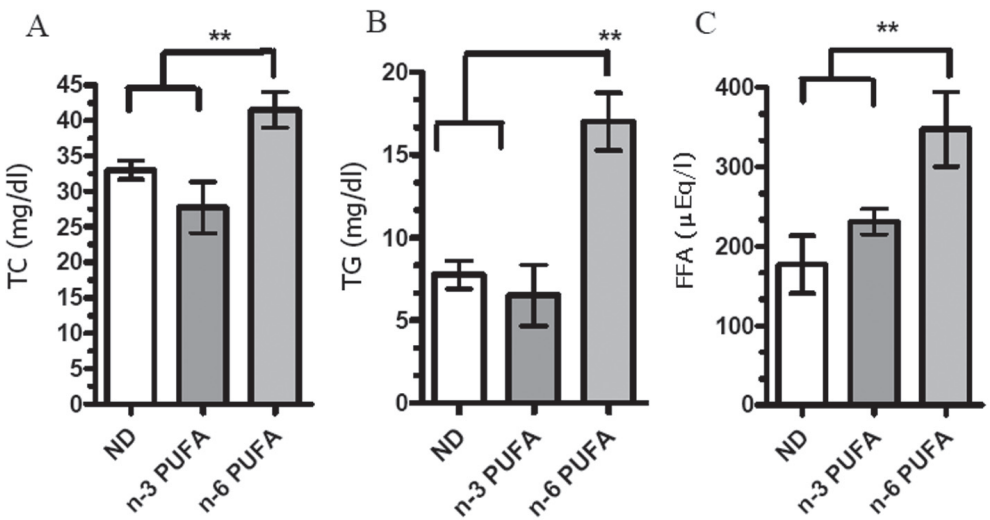

Figure 3. Effects of ND, n-3 PUFA and n-6 PUFA on plasma levels of TC (A), TG (B) and FFA (C). TC, total cholesterol; TG, triglyceride; FFA, free fatty acid; ND, normal diet; n-3 PUFA, EPA and DHA diet; n-6 PUFA, AA diet. Values represent mean \pm S.E.M $(n=8) ;{ }^{* *} p<0.01$.

At the same time, plasma LDL level for n-6 PUFA group was significantly higher $(p<0.5)$ compared to control group as shown in Fig. 4B.

Measurement of plasma PL showed 2.3-fold increase in n-6 PUFA group compared to n-3 PUFA group $(p<0.01)$ while this elevation was only 1.6 -fold compared to control group $(p<0.01)$ (Fig. 4 C). On the other hand, plasma HDL and glucose levels did not changed significantly between experimental groups (Fig. 4A,D).

\section{PCR}

PCR amplification and image analysis of $o b, o b R$ and GAP$\mathrm{DH}$ are shown in Fig. 5. Our findings showed that $o b$ mRNA in epididymal fat was increased significantly $(p<0.01)$ in n-6 PUFA regime while no change was observed between control (ND) and n-3 PUFA. On the other obRa gene expression was not affected in response to different diet regimes.

\section{Transmission and scanning EM}

The number, size, and content density of lipid droplets in the hepatic parenchymal cell varied dramatically between experimental groups. In ND, there were few lipid droplets distributed throughout the cytoplasm which appeared round to ovoid electron lucent bodies of medium to large size (Fig. $6 \mathrm{~A}, \mathrm{~B})$. On the other hand, hepatic ultrastructure of n-3 PUFA fed group revealed higher number of lipid droplets than in 

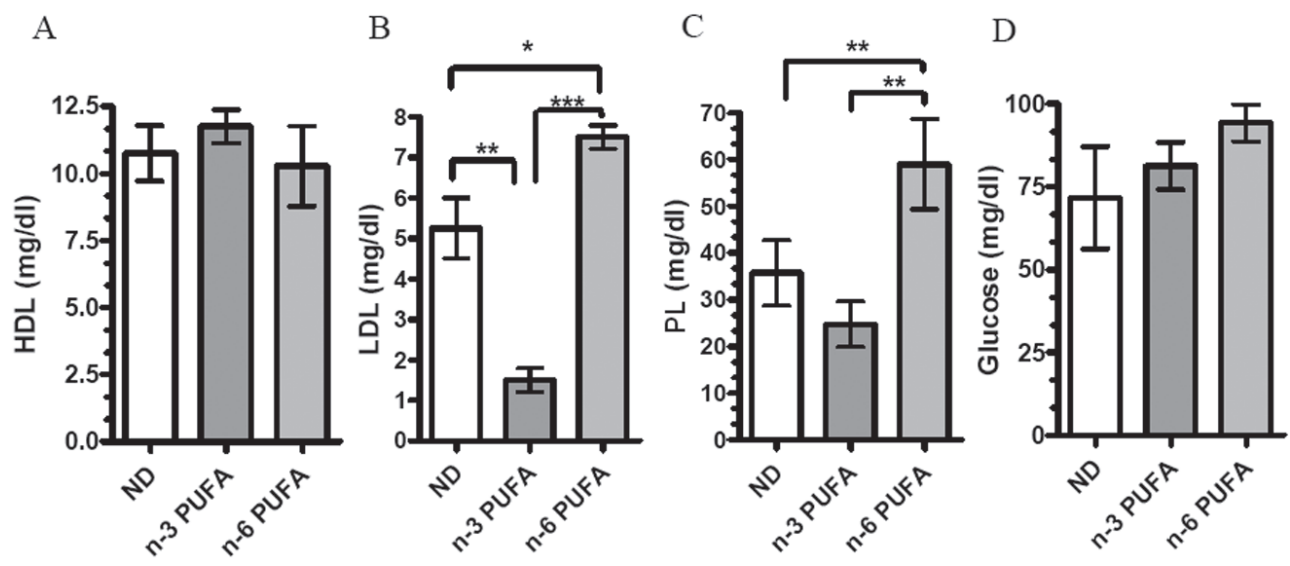

Figure 4. Effects of ND, n-3 PUFA and n-6 PUFA on plasma levels of HDL (A), LDL (B), PL (C), and glucose levels (D). HDL, high density lipoprotein; LDL, low density lipoprotein; PL, phospholipids; ND, normal diet; n-3 PUFA, EPA and DHA diet; n-6 PUFA, AA fat diet. Values represent mean \pm S.E.M $(n=8) ;{ }^{\star} p<0.05,{ }^{* *} p<0.01,{ }^{* * *} p<0.001$.
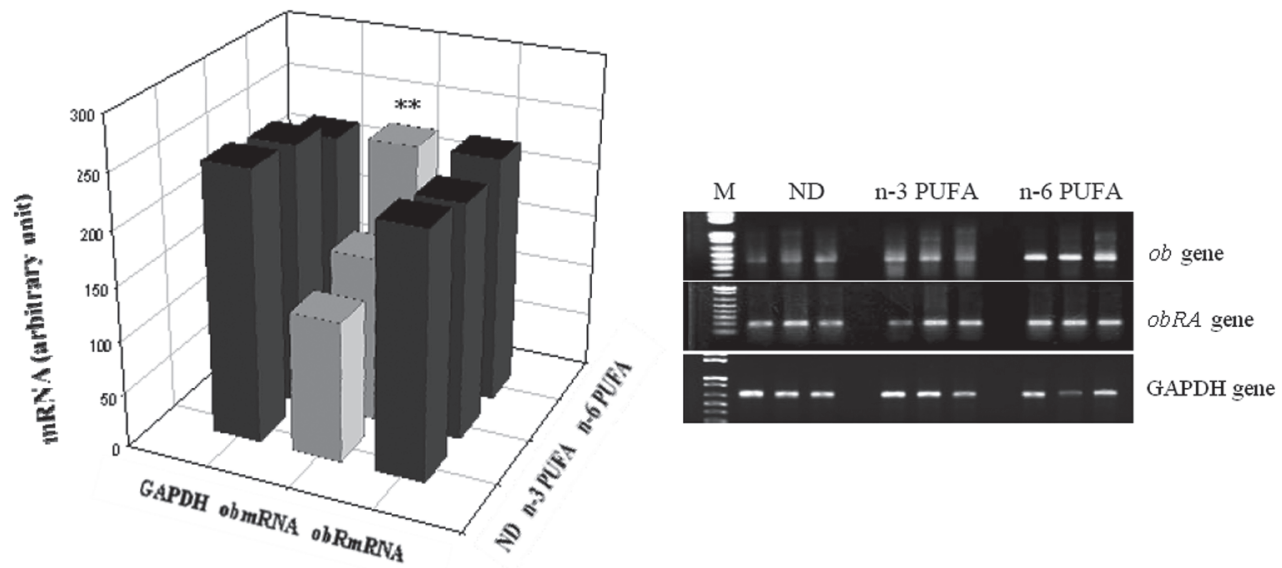

Figure 5. RT-PCR amplified mRNA of $o b$, $o b R a$, and GAPDH. $o b$, leptin; $o b R a$, leptin receptor A; GAPDH, glyceraldehyde-3-phosphate dehydrogenase; M, 1 kb plus DNA ladder (invitrogen); ND, normal diet; n-3 PUFA, EPA and DHA diet; n-6 PUFA, AA high fat diet. ${ }^{* *} p<0.01$ comparing to other group.

control group with relatively small to medium electron dense droplets (Fig. 6C,D). The ultrastructural configuration of n-6 PUFA fed mice showed higher number of lipid droplets than the other experimental groups. The majority appeared as small electron dense droplets distributed throughout the cytoplasm with fewer medium to large size (Fig. 6E,F).

Ito cells or hepatic stellate cells; pericytes found in the perisinusoidal space of the liver, contained few numbers of electron lucent small oval lipid droplets in control and n-3 PUFA fed groups (Fig. 6G) while these lipid droplets were extremely large electron dense and occupying most of the Ito cells cytoplasm in n-6 PUFA fed group (Fig. 6H). In some cases, the over accumulation of these lipids lead to repositioning the nucleus eccentrically (Fig. 6H).
Scanning EM results showed normal architecture of liver in ND and n-3 PUFA groups (Fig. 7A) on the other hand, an extensive deposition of lipid droplets on the surface scan of n-6 PUFA group hepatocytes (Fig. 7B). Furthermore, a freeze in depth cut section confirmed this observation in n-6 PUFA group but not in ND or n-3 PUFA fed mice.

\section{Discussion}

The present study investigated some physiological effects of n-3 PUFA and n-6 PUFA supplementation on weight gain, lipid profile, ultrahepatic structural changes and gene expression levels of $o b$ and $o b R a$ in epididymal adipose tis- 

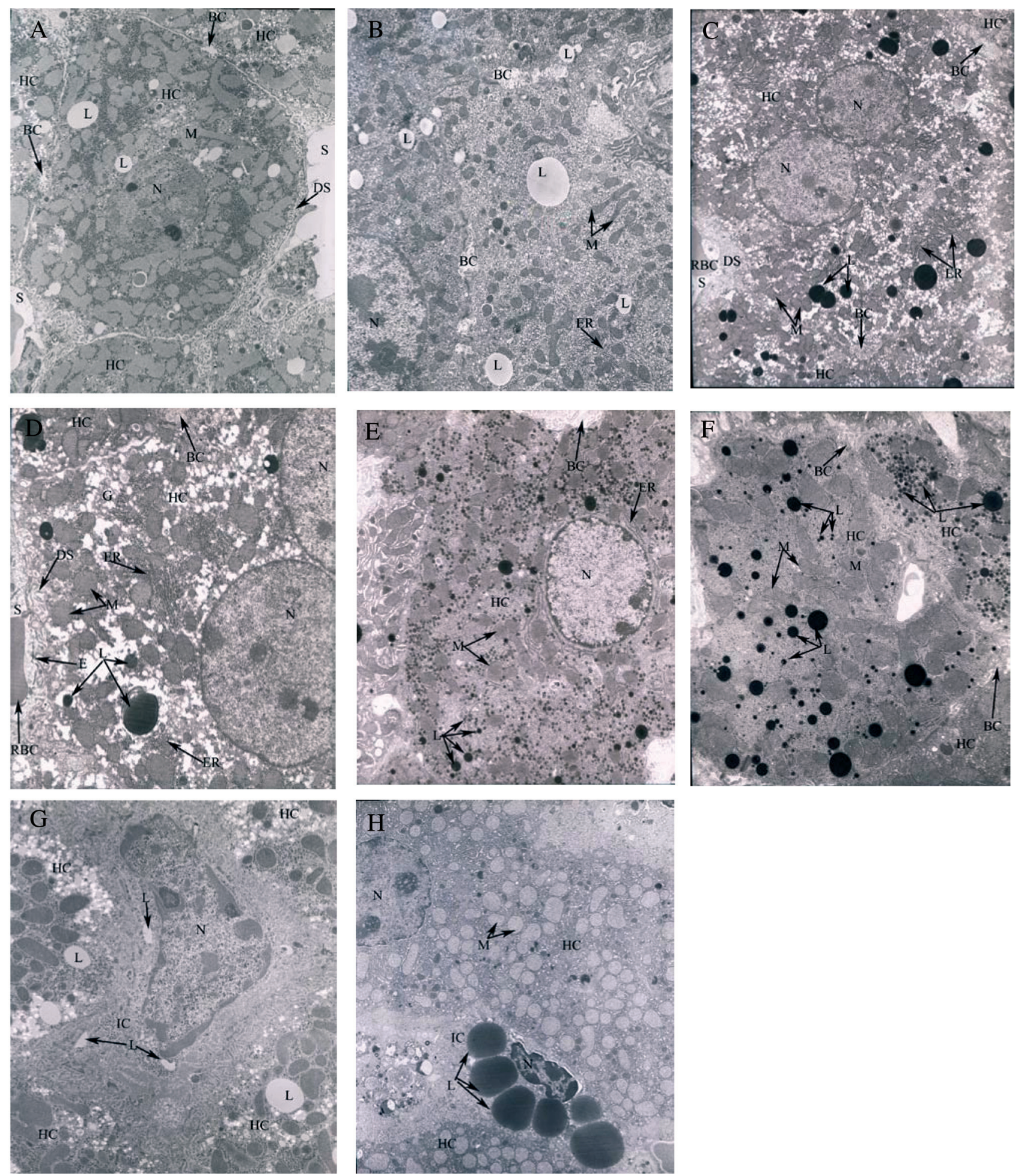

Figure 6. Transmission electron micrographs illustrate intracellular organization and fat droplets accumulation in hepatocytes of ND (A, B), n-3 PUFA (C, D), n-6 PUFA (E, F) groups, and Ito cells (G, H). HC, hepatocyte; ER, rough endoplasmic reticulum ; M, mitochondria; G, glycogen granules; BC, bile canaliculi; S, sinusoids; D, space of disse; L, lipid droplet; RBC, red blood cell; N, nucleus; E, endothelial cell; IC, Ito cell. Magnification $\times 2000$. 

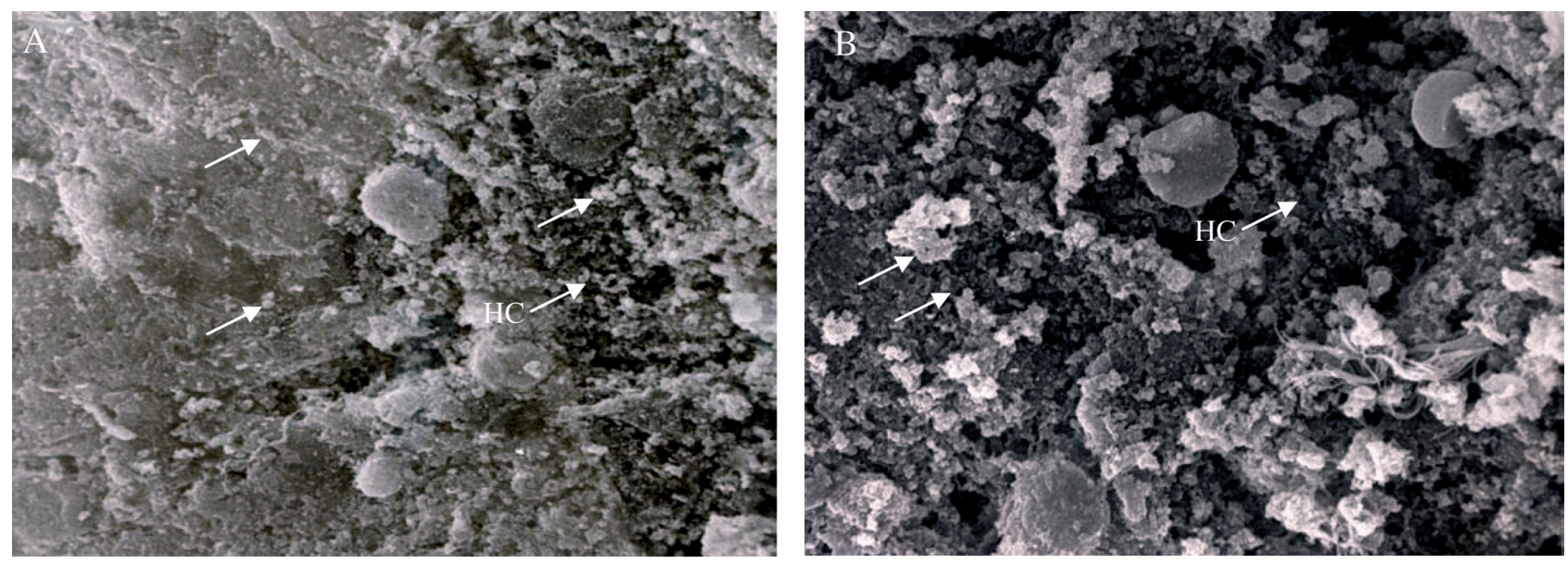

Figure 7. Scanning electron micrographs illustrate extracellular hepatocytes organization and fat accumulation in ND (A) and n-6 PUFA (B) groups. Lipid droplets (arrows); HC, hepatocyte. Magnification $\times 120$.

sue and hypothalamus, respectively, under different PUFA diet regimen.

In the current study, diet consumption of n-6 PUFA fed mice was significantly decreased to $49 \%$ compared to ND and n-3 PUFA fed group (84.6 and 72\%), respectively. This observation denotes lowered appetite of n-6 PUFA fed mice as a consequence for elevated $o b$ transcription (as shown later). Taking in consideration the outcomes of previous reports denoted that not all PUFAs exhibit appetizing effect (Fain et al. 2001; Li et al. 2008), together with our finding that mice fed on a diet rich in AA (n-6 member) consumed an average diet less that control group, it is likely to propose an anti-appetizing effect of dietary AA. On the other hand, body weight gain of n-6 PUFA fed mice significantly $(p<$ 0.05 ) increased at day 7 compared to ND and n-3 PUFA fed groups and became highly significant $(p<0.01)$ thereafter. The close non-significant body weights between n-3 PUFA and ND fed groups agrees with previous experimental works which reported that dietary EPA and DHA shows a little effect on body weight gain (Hun et al. 1999; Gaiva et al. 2001). Similarly, West et al. (2000) found that n-3 PUFA reduces adipose depot weights by $\sim 50 \%$ without any significant effect on either body weight or energy intake. This effect presumably due to reduction of fat mass at specific fat depots (i.e. retroperitoneal and epididymal white fat), and thought to be partially mediated via inducing a thermogenic activity of the adipose tissue ( $\mathrm{Li}$ et al. 2008). On the other hand, n-6 PUFA fed mice showed prominent increase in body weight with obvious accumulation of adipose tissue especially in the abdomen and epididymas, a condition associated with elevated $o b$ expression level and probably other endocrine factors. To further clarify this phenomenon, plasma lipids were measured since it clearly indicates the status of lipid metabolism. As shown in Fig. 3, plasma TC, TG, FFA and
PL did not change significantly between ND and n-3 PUFA groups. Recent studies have reported that both EPA and DHA have an anti-obesity effect through inhibition of FA synthesis (FAS) and promoting mitochondrial FA $\beta$-oxidation (Guo et al. 2005, Li et al. 2008). Furthermore, expression of many lipogenetic enzymes as sterol-CoA desaturase (SCD) is regulated by the transcription factor, sterol regulatory element-binding protein (SREBP-I) that plays a role in hepatic lipogenesis (Tsuzuki et al. 2006). Recently it was also reported that both EPA and DHA improve lipid profile by mechanism associated with decreasing SREBP-I (Nakatani et al. 2003). This evidence indicates the inhibitory effect of both EPA and DHA on FAS and SCD via their suppression of SREBP-I. Once again, according to Raclot et al.(1997), they reported that feeding rats with DHA diet and DHA-EPA mixed diet was associated with significant reduction in levels of hormone-sensitive lipase. The later is a cytosolic neutral lipase that hydrolyzes intracellular TG stored within adipocytes and produce FFA. All above data support the notion that n-3 PUFA improves lipid metabolism.

Interestingly, long-term feeding on n-6 PUFA resulted in marked elevation of TC, TG, FFA and PL levels. It is important to mention that metabolites of n-3 PUFA resulted in signaling molecules termed eicosanoids while n-6 PUFA metabolized into pro-inflammatory mediators termed prostanoids. Both eicosanoids and prostanoids bind to a group of nuclear receptor proteins called peroxisome proliferative activated receptors (PPARs). The later plays an essential role in stimulating $\beta$-oxidation process and decreasing SREBP-I. Recently, it was proved that the affinity of EPA and DHA (or their metabolites) as a ligand to PPAR is much higher than in AA (or its metabolite) (Li et al. 2008; Schmitz and Ecker 2008). Therefore, it is acceptable to mention that n-3 PUFA is much potent than n-6 PUFA in improving lipid profile. Similarly, 
a better anti-obesity effect was reported when comparing between DHA (n-3 PUFA member) and linoleic acid (LA; n-6 PUFA member) (Tsuzuki et al. 2006). The authors explained this observation due to the different location and number of double bond and carbon atoms within each FA.

LDL dramatically elevated in n-6 PUFA fed mice as shown in Fig. 4B. This elevation is expected under high fat diet condition because most of LDL consists of CL and PL that were elevated in the same group. Moreover, a transient elevation of LDL might be seen in some PUFA supplementation (Harries 1997). On the other hand, LDL levels significantly decreased in n-3 PUFA fed mice comparing to ND. This decrease is probably due to rapid uptake of lipids by the peripheral tissues.

Our results revealed a nonsignificant effect on HDL fraction between groups. The same finding was reported earlier by Harries (1997). This might be due to the fact that HDL consists mainly of protein fraction rather than lipid fraction. Moreover, dietary PUFA may increase $\mathrm{HDL}_{2}$ sub fraction without increasing total HDL level (Hill et al. 2007).

Although some previous studies revealed anti-diabetic effect of PUFAs, our results did not show any significant difference in plasma glucose levels (Fig. 4D). This might be due to the different potentiality of these lipids on glucose pathway owed to the differences in number of carbon atoms and double bonds.

To further strengthen the validity of our experimental outcomes, mRNA gene expression levels of $o b$ gene in epididymal adipose tissue and $o b R a$ gene in hypothalamus were examined.

As shown in Fig. 5, ob gene expression markedly elevated in n-6 PUFA fed mice but not in ND or n-3 PUFA groups. Similarly, it was found that AA or prostaglandin $\mathrm{E}_{2}$ elevated $o b$ mRNA levels of the subcutaneous adipose tissue explants in mammals (Trayhurn et al. 1995; Fain et al. 2001). The stimulatory effect of AA on $o b$ formation can be blocked by a cyclooxygenase- 2 inhibitor which refutes the possibility that transcriptional $o b$ levels increased in response to conversion of AA by lipooxygenase or epoxides. Hence it is likely to consider that $o b$ stimulation by AA is probably secondary to conversion to a prostanoids. Our results support the hypothesis that under appropriate conditions, endogenous prostanoids regulate lipolysis and aid in $o b$ synthesis in adipocytes (Fain et al. 2001). On the other hand, EPA and DHA improved lipid profile and prevented hyperlipidemia in $n-3$ PUFA group and consequently lowered the transcription of $o b$ gene from adipocytes.

$o b R$ is a member of class I cytokine receptors which are known to act through cytoplasmic tyrosine kinases of the Janus kinase family (JAKs) and signal transducers and activators of transcription (STAT) (Geerts and Hautekeete 1997). At least 6 spliced isoforms ( $o b R a-o b R f)$ were discovered yet (Tartaglia 1997). In the current experiment, we measured one of the short splice forms $(o b R a)$ in the hypothalamus. Result shown in Fig. 5 revealed that $o b R a$ did not significantly affected within the tested groups although $o b$ gene prominently elevated in n-6 PUFA fed mice. This result might be due to in ability of $o b R a$ to activate JAK/STAT pathway. Li et al. (2008) suggested that absence of box 2 in $o b R a$ which is physiologically important might be the cause for its signaling inactivity.

The reason why these forms of $o b R$ are produced and their respective roles are still not clear. It has been suggested that the short form in the choroid plexus and hypothalamus plays a role in transporting $o b$ from the blood into cerebrospinal fluid (Geerts and Hautekeete 1997; Tartaglia 1997; Li et al. 2008) where it can move by diffusion to the brain centers that regulate body weight. A previous study by Kastin et al. (1999) found that transport of $o b$ across the blood-brain barrier in rat lacking $o b R a$ was decreased denoting that $o b R a$ may have a functional role in $o b$ transport. However, in another experiment, it was found that $o b R a$ was able to activate JAK tyrosin phosphorylation in a $o b$-dependent manner in transfected cell line (Bjorbaek et al. 1997). The exact role of $o b R a$ would require more extensive experimentation to be confirmed.

Alterations in liver tissue were evaluated by ultrahepatic examination using transmission and scanning EM. Surprisingly, both n-3 and n-6 PUFA groups showed critical ultrahepatic modification in both lipid droplets and Ito cells. Prominent changes in the lipid droplets number, intensity and size were detected as shown in Fig. 6A-F. In a previous report on LA (n-6 member), it was reported that over feeding of rats induces fatty liver and stenosis in most cases (Nakanishi et al. 2004). Similarly, in another study using different LA mixture, it demonstrated that compared to LA, conjugated LA led to hepatomegaly with fatty deposition in both C5BL/6J and ICR mice (Takahashi et al. 2003). This observation supports the statement that it might be an isomer-dependent. On the other hand, it is unclear why n-3 PUFA fed mice livers showed abnormal ultrastructure. Possibly due to the extensive fat diet in the current study $(\approx 15 \%)$. Ito cells were overfilled with fat droplets in n-6 PUFA group, a condition that reflects over accumulation of fat and extraenergy reserve while it was in a quiescent state in ND and n-3 PUFA fed mice. Scanning EM supported the results of transmission EM, surface scanning and indepth-freeze sections showed intense accumulation of lipid droplets between hepatocytes of n-6 PUFA fed group but not ND or n-3 PUFA fed groups (Fig. 7A,B). Taking in consideration that those groups were fed a high fat diet, the EM observation presumably denotes a possible earlier stage of fatty liver in n-6 PUFA fed mice with milder form in n-3 PUFA group. Furthermore, it directs us to the masked organ alteration despite acceptable plasma profile of n-3 PUFA group. In conclusion, n-3 PUFA is much potent than n-6 PUFA in improving plasma lipogram but although EPA and DHA showed excellent lipid 
plasma profile, the coincidently structural changes observed in liver of this group direct us to call for further studies to investigate the anti-obesity effect and safety of these PUFAs under high supplementation condition.

Acknowledgment. The authors thank Prof. Adel Siam for his valuable guidance and assistances.

\section{References}

Bjorbaek C. U., Da Silva B., Flier J. S. (1997): Divergent signaling capacities of the long and short isoforms of the leptin receptor. J. Biol. Chem. 272, 32686-32695; doi:10.1074/ jbc.272.51.32686

Fain J. N., Leffler W. C., Cowan G. S. Jr., Buffington C., Pouncey L., Bahouth S. (2001): Stimulation of leptin release by arachidonic acid and prostaglandin E2 in adipose tissue from obese humans. Metabolism 50, 921-928; doi:10.1053/meta.2001.24927

Gabriel B. L. (1982): Biological Scanning Electron Microscopy. 1st edition. CRC Press, Boca Raton

Gaiva M. H., Couto R. C., Oyama L. M., Couto G. E. (2001): Polyunsaturated fatty acid-rich diet: effect on adipose tissue metabolism in rats. Br. J. Nutr. 86, 371-377; doi:10.1079/ BJN2001392

Geerts A., Hautekeete M. (1997): The hepatic stellate (Ito) cell: its role in human liver disease. Virchows Arch. 430, 195-207; doi:10.1007/BF01324802

Guo W., Xie W., Lei, T., Hamilton J. A. (2005): Eicosapentaenoic acid, but not oleic acid, stimulates beta oxidation in adipocytes. Lipids 40, 815-821; doi:10.1007/s11745-005-1443-8

Harries W. S. (1997): n-3 fatty acids and serum lipoproteins: human studies. Am. J. Clin. Nutr. 65, S1645-1654

Hill A., Buckley J., Murphy K., Howe P. (2007): Combining fish oil supplementation with regular aerobic exercise improves body composition and cardiovascular risk factors. Am. J. Clin. Nutr. 85, 1267-1274

Hun C. S., Hasegawa K., Kawabata T., Kato M., Shimokawa T., Kagawa Y. (1999): Increased uncoupling protein 2 mRNA in white adipose tissue, and decrease in leptin visceral fat, blood glucose, and cholesterol in KK-Ay mice fed with eicosapentaenoic and docosahexaenoic acids in addition to linolenic acid. Biochem. Biophys. Res. Commun. 259, 85-90; doi:10.1006/bbrc.1999.0733

Kastin A. J., Pan W., Maness L. M., Koletsky R. J., Ernsberg P. (1999): Decreased transport of leptin across the blood-brain barrier in rats lacking the short form of the leptin receptor. Peptides 20, 1449-1453; doi:10.1016/S0196-9781(99)00156-4

Li J. J., Huang J., Xie D. (2008): Anti-obesity effects of conjugated linoleic acid, docosahexaenoic acid and eicosapentaenoic acid. Mol. Nutr. Food Res. 52, 1-15; doi:10.1002/ mnfr.200700399

Nakanishi T., Oikawa D., Koutoku T., Hirakawa H. (2004): Gammalinolenic acid prevents conjugated linoleic acid-induced fatty liver in mice. Nutrition 20, 390-393; doi:10.1016/ j.nut.2003.12.014
Nakatani T., Kim H., Kaburagi Y., Yasuda K., Ezaki O. (2003): A low fish oil inhibits SREBP-1 proteolitic cascade, while a highfish oil feeding decreases SREBP-1 mRNA in mice liver: relationship to anti-obesity. J. Lipid Res. 44, 369-379; doi:10.1194/jlr.M200289-JLR200

Raclot T., Groscolas R., Langin D., Ferré P. (1997): Site-specific regulation of gene expression by $n-3$ polyunsaturated fatty acids in rat white adipose tissues. J. Lipid Res. 38, 1963-1972

Reseland J. E., Haugen F., Hollung K., Solvoll K., Halvorsen B., Brude I. R., Nenseter M. S., Christiansen E. N., Christain A. D. (2001): Reduction of leptin gene expression by dietary polyunsaturated fatty acids. J. Lipid Res. 42, 743-750

Rozen S., Skaletsky H. J. (2000): Primer3 on the WWW for general users and for biologist programmers. In: Bioinformatics Methods and Protocols: Methods in Molecular Biology. (Eds. S. Krawetz and S. Misener), pp. 365-386, Humana Press, Totowa, New Jersey

Schmitz G., Ecker J. (2008): The opposing effects of n-3 and n-6 fatty acids. Lipid Res. 47, 147-155; doi:10.1016/ j.plipres.2007.12.004

Takahashi Y., Kushiro M., Shinohara K., Ide T. (2003): Activity and mRNA levels of enzymes involved in hepatic fatty acid synthesis and oxidation in mice fed conjugated linoleic acid. Biochem. Biophys. Acta 1631, 265-273

Tartaglia L. A. (1997): The leptin receptor (Minireview). J. Biol. Chem. 272, 6093-6096

Trayhurn P., Thomas M., Duncan J., Rayner D. (1995): Effects of fasting and refeeding on ob gene expression in white adipose tissue of lean and obese (ob/ob) mice. FEBS Letter 368, 488-490; doi:10.1016/00145793(95)00719-P

Trayhurn P., Hoggard, N., Mercer J. G., Rayner D. V. (1999): Leptin: fundamental aspects. Int. J. Obes.Relat. Metab. Disord. 23 (Suppl. 1), 22-28; doi:10.1038/sj.ijo.0800791

Tsuzuki T., Kawakami Y., Suzuki Y., Abe R., Nakagawa K., Miyazawa T. (2005): Intake of conjugated eicosapentaenoic acid suppresses lipid accumulation in liver and epididymal adipose tissue in rats. Lipids 40, 1117-1123; doi:10.1007/ s11745-005-1475-0

Tsuzuki T., Kawakami Y., Nakagawa K., Miyazawa T. (2006): Conjugated docosahexaenoic acid inhibits lipid accumulation in rats. J. Nutr. Biochem. 17, 518-524; doi:10.1016/ j.jnutbio.2005.09.006

Wang H., Storlien L. H., Huang X. (2002): Effects of dietary fat on body fatness, leptin, and ARC leptin receptor, NPY and AgRP mRNA expression. Am. J. Physiol., Endocrinol. Metab. 282, E1352-1359

West D. B., Blohm F., Truett A. A., DeLany J. P. (2000): Conjugated linoleic acid persistently increases total energy expenditure in AKR/J mice without increasing uncoupling protein gene expression. J. Nutr. 130, 2471-2477

Williams D. B., Carter C. B. (2006): Transmission Electron Microscopy: a Textbook for Materials Science. Vol. 4, New York Plenum Press, USA

Received: September 9, 2008

Final version accepted: January 20, 2009 